\title{
La educación y la formación en la Educación Normal
}

\author{
Martha Yolanda Monzón Troncoso
}

Escuela Normal de Ixtapan de la Sal

\begin{abstract}
No quiero convencer a nadie de nada. Tratar de convencer a otra persona es indecoroso, es atentar contra su libertad de pensar o creer o de hacer lo que le dé la gana. Yo quiero sólo enseñar, dar a conocer, mostrar, no demostrar. Que cada uno llegue a la verdad por sus propios pasos, y que nadie le llame equivocado o limitado. ¡Quién es quién para decir "esto es asi", si la historia de la humanidad no es más que una historia de contradicciones $y$ de tanteos y de búsqueda!
\end{abstract}

Jaime Sabines

\section{Resumen}

$\mathrm{E}$ $\mathrm{n}$ este artículo se analiza el proceso de formación en educación normal. Se reflexiona sobre la construcción de dos categorías subjetivadas: la educación y la formación desde una visión en el ámbito educativo, sin negar su presencia en el terreno filosófico, sociológico e incluso pedagógico. Se abre el análisis de los conceptos desde el ámbito de la educación normal, ¿ dónde se forman o educan sujetos?, lo que constituye, sin duda, una ocasión para formarse. Se hace un análisis respecto a su impacto en la formación de docentes, con una revisión epistémica, que permite una mirada que converge, para ir de la teoría a la praxis y a la inversa. Se recuperan diferentes autores para acceder al análisis y comprensión de los conceptos: educación y formación, así como su relación, siendo categorías que confluyen entre sí, en un importante papel en cuanto a la formación de docentes con los dispositivos allí involucrados, para la construcción de sujetos.

Palabras clave: educación, formación, discursos, dispositivo. 


\section{Introducción}

Este artículo tiene como propósito acercarse a la comprensión de dos procesos: la educación y la formación desde un horizonte epistemológico y su inserción en la educación normal, con el educador o formador de sujetos. En la primera parte se presenta un análisis de su génesis a través de la historia del hombre. Dos categorías subjetivadas en un marco de saberes que se entrecruzan en un quehacer cotidiano, en una escuela donde se forman docentes. Se presenta un análisis de cada concepto en específico para después conjuntarlos y poder comprender su relación en un vínculo donde la educación se constituye en un proceso social y la formación en uno personal, en un trabajo sobre sí mismo. El papel de la educación, de la formación y sus dispositivos, están implicados en el rol del formador como "constructor de sujetos".

\section{Educación y formación: perspectivas epistemológicas}

\subsection{Educación}

La Educación es consustancial de la vida del hombre como individuo y de la sociedad de la que forma parte. Responder ¿qué es la educación? implica ir a los orígenes de la palabra, del latín educere, sacar, extraer o educare, formar, instruir. Kant menciona que la educación es el proceso por medio del cual el hombre llega a ser lo que es, es el medio que permite la transformación (citado por Cabedo y Gil, 2013). La educación además de ser una función social, también es una necesidad, una tarea a desarrollar por ámbitos disímiles.
La educación es una práctica histórica. La "necesidad de transmisión" de conocimiento es un eslabón que ha permeado toda acción. Repensar esta categoría refiere nuevas formas de reflexionar. La educación es "un mal necesario" de transmisión de saberes, actitudes, habilidades, capacidades y ahora "competencias",de las generaciones adultas a las jóvenes. En la vida del hombre la educación permea en cada uno de sus actos desde el inicio de la vida; por ella se transmiten valores, creencias, saberes y formas diversas de comportamiento de manera natural desde el origen de la especie humana, este proceso ha permitido su desarrollo y evolución.

La educación es un fenómeno social, inicia por el núcleo más pequeño, la familia. Así se ve como la acción que ejercen los adultos sobre los menores. La educación es una tradición, inicia en el hogar y continúa en la escuela, como un proceso de escolarización, que además es un dispositivo ${ }^{1}$. En la escuela el niño empieza a atender una serie de circunstancias que le "preparan para la vida futura" en todas sus dimensiones. A la manera de Foucault, la educación es generadora de saber y en su esencia, constituye poder (1975: 210). La educación implica la transmisión de formas de comportarse desde el inicio de la vida, sin negar con ello una "red de relaciones complejas" (Elliot, 1995: 61) que le generan estructuras, pero también rupturas.

En la educación, la experiencia, los sentimientos y las intenciones se van configurando en una sedimentación inicial de la conducta humana que tiene su origen en la historicidad del hombre, a la que se somete 
o se resiste. Cuestiona Gadamer:

¿Estar sometido en tradiciones significa real y primariamente estar sometido a prejuicios y limitado en la propia libertad? ¿No es más bien que toda existencia humana, aún la más libre, está limitada y condicionada de muchas maneras?... la razón no es dueña de sí misma sino que está siempre referida a lo dado en lo cual se ejerce (1988: 343$)$.

Más adelante expresa: "El hombre es extraño a sí mismo y a su destino histórico de una manera muy distinta a como le es extraña la naturaleza, la cual no sabe nada de él" (Gadamer, 1988: 343). Sus juicios obedecen a atrincheramientos a los que responde, porque la tradición lo establece, incluso a ciertas formas o tipos de educación, en el marco de una comprensión histórica.

La educación en la escuela, encabeza el encierro, el sometimiento, pero también la conformación del yo, de un sujeto con identidad en constitución de su vida social. Así va forjando un "suceso estructurador" que le permite romper la "mónada de la psique" para hacer entrar "al sujeto individual en la red de relaciones sociales y culturales preexistentes" (Elliot, 1995: 61). El sujeto requiere una conformación del yo en relación con el otro, la educación busca la formación integral del individuo, escolarizada o no. Más allá de discursos en el aula, en los procesos de enseñanza y aprendizaje se busca generar una conciencia colectiva que beneficie al individuo y a la sociedad a través de la relación con los otros, algunas veces mediante el sometimiento, otras en espacios de libertad y convivencia.
Hay un sinfín de discursos redentores con respecto a la educación entendida como factor esencial para el desarrollo individual y social. La UNESCO recupera trabajos interesantes en relación específica con el campo educativo, uno de ellos son los cuatro pilares de la educación: “aprender a conocer, aprender a ser, aprender a vivir juntos y aprender a ser" (Delors, 1994). Éstos no solo son rescatables en la escuela, como institución educativa para los niños y los jóvenes, sino también para los adultos y forman parte de un discurso que habría que cuestionarse si ¿forman parte de una práctica cotidiana?

\subsection{Formación}

Si tomo un objeto moldeable, lo manipulo, le doy alguna forma, ¿de allí viene el término formación? se puede constituir como un proceso moldeable ¿que deviene del exterior? La formación ¿es una acción sobre el sujeto para formarlo y transformarlo?, parece que no. Hegel, Gadamer, Foucault, Ferry y Zambrano, entre otros, no estarían de acuerdo con esto. Iniciamos con Gadamer dada su importancia en el campo epistemológico, quien es influido por Hegel: "En la Fenomenología del espíritu, Hegel desarrolla la génesis de una autoconciencia verdaderamente libre «en y para sí» misma, y muestra que la esencia del trabajo no es consumir la cosa, sino formarla" (1988: 41).

Siguiendo a Hegel, habíamos destacado como característica general de la formación, este mantenerse abierto hacia lo otro, hacia puntos de vista distintos y más generales. La formación comprende un sentido 
general de la mesura y de la distancia respecto a sí mismo, y en esta misma medida un elevarse por encima de sí mismo hacia la generalidad. Verse a sí mismo y ver los propios objetivos privados con distancia, quiere decir verlos como los ven los demás. $\mathrm{Y}$ esta generalidad no es seguramente una generalidad del concepto o de la razón. No es que lo particular se determine desde lo general; nada puede aquí demostrarse concluyentemente (Gadamer, 1988: 46).

Gadamer menciona que "en la formación alcanzada nada desaparece, sino que todo se guarda" (1988: 40), fundamenta un papel importante en la experiencia "esencia de la formación”. Humboldt enuncia: "La formación es un modo de percibir que procede del conocimiento y del sentimiento de toda vida espiritual y ética y se derrama armoniosamente sobre la sensibilidad y el carácter" (citado por Gadamer, 1988: 39).

"La formación pasa a ser algo muy estrechamente vinculado al concepto de cultura y designa en primer lugar el modo específicamente humano de dar forma a las disposiciones y capacidades naturales del hombre" (Gadamer, 988: 39). La formación posee un sentido de apropiación, no de compra, sino espiritual. El sujeto va adquiriendo o tomando del exterior todo aquello que lo va erigiendo, reconociendo un interior que mueve a ser lo que "se es", a través de lo que uno va instituyendo en lo que "se es".

La formación se busca, el sujeto debe saber qué quiere, no es algo que se adquiere de una vez y para siempre, a lo que acceden solo unos y no otros. No se consigue con un documento, se da en una relación "para" y en concordancia con objetivos que se pretenden alcanzar. La formación es como una acción que emerge proyectada con ese "fiat voluntario" que plantea Schütz, lo "motivado del modo para... la decisión ¡adelante! que transforma el fantaseo interno en una efectuación o una acción inserta en el mundo externo" (2008: 88). Con la manera en que el sujeto que vive de su acción en curso le da sentido y significado. Es una característica propia de la persona que le constituye como sujeto que se cultiva y puede "desplegar", no tiene espacio o tiempo, edad o escuela.

Tener como tarea "realizar una formación" está justificado. Pero realizar una formación no es más que, en el mejor de los casos una ocasión para formarse. Aunque es verdad que ninguna persona se forma a través de sus propios medios (es necesario tener mediaciones), tampoco se puede formar por un dispositivo, ni por otra persona (Ferry, 1990: 42).

Ferry (1990) plantea dos sentidos del término formación; uno se refiere al trabajo sobre sí mismo, del desarrollo del sujeto; otro como la función dentro de una sociedad en un "contexto histórico y cultural". Lo social se realiza y legitima a través de la escuela como "dispositivo de formación". Ferry rescata la tradición humanista de Gadamer quien plantea a la formación "como ascenso a la generalidad, una tarea humana que requiere sacrificio de la particularidad a favor de la generalidad" (Gadamer, 1988: 41).

En La hermenéutica del sujeto Michel Foucault plantea "el cuidado de sí mismo", 
“ocuparse de sí mismo" y "conócete a ti mismo", circunscribe su significación como transformación del sujeto en la búsqueda de objetivación, de la verdad con saberes que respondan a una formación del sujeto a partir del trabajo, la interacción y el lenguaje, sin ello no se posibilita. "La formación implica un trabajo del ser humano sobre sí mismo, sobre sus representaciones y conductas; viene a evocarse como el advenimiento ineludible del orden de las cosas" (2002: 46). Y así, en todos los espacios, con los horizontes que dan sentido y estructuración al mundo de la vida cotidiana, permitiendo una actuación diferenciada en función del interés concomitante que se va despertando en la relación con los otros.

La formación es "mucho más raramente mencionada desde el punto de vista del sujeto, de la interioridad, como una dimensión característica de la persona" (Honore, 1980: 20). La formación no se da de manera individual, se adquiere con el otro, con los contemporáneos. Se busca que un saber que se introyecta sea "absorbido" por el sujeto y evolucione para ser superado y revelado al exterior, de manera diferente "enriquecido, con significado en una nueva actividad" (Honore, 1980: 20). La formación se busca, la persona debe saber lo que quiere. "Aristóteles ya se había percatado de que la formación en cuanto que autocercioramiento del hombre solo es posible desde la distancia reflexiva frente a un aprendizaje por la experiencia y el trato social" (Benner, 1998: 234). Reflexionar supone una trascendencia de la experiencia.

Dentro de este marco, hay puntos de encuentro y desencuentro, es necesario contar con una mirada amplia, la óptica de la formación se encuentra en función de diferentes percepciones, que sin embargo, coexisten. La formación como una función social, "transmite" el saber, el saber hacer o el saber ser "que se ejerce en beneficio de un sistema socioeconómico o más generalmente de una cultura dominante" (Ferry, 1990: 50).

Zambrano dice que "no hay formación solo por la capacidad y el conocimiento promovido" (2007: 40) puntualiza la experiencia como fundamental, así como al saber que nutre. La formación es un trayecto que inicia al nacer, pero no culmina al ingresar a la cultura adulta se entra en un proceso de formación que se va consolidando, pero no termina.

Sobrino menciona que la noción de formación es heredada de los griegos, con el sentido de educación liberal, entendida como paideia, cuyo fin es en esencia la formación integral del hombre, "del cuerpo, del alma, el ánimo y la mente, lo volitivo y lo intelectivo... paideia es al mismo tiempo un resultado: el hombre mismo alcanza la estatura perfecta y los elementos modeladores con los que tal logro es obtenido" (2011: 41). Las dimensiones ético políticas están implicadas en la educación, en la formación, en la búsqueda de una "vida buena”.

El saber y la experiencia son parte fundamental de la formación, inicia con la educación, "abre la puerta a la formación" con el sentido, la comprensión, la experiencia y el saber e incluso el saber de sí. La formación si bien a la manera de Foucault im- 
plica el trabajo sobre sí mismo, es también una ocasión por medio de la educación para la formación. Se constituye en un proceso permanente de cada sujeto, que se instituye como tal sobre sí mismo, en su relación y mediación con los otros, rescatando de sí esa voluntad de conformación de un sujeto y no de otro con su conformación de un yo, en un nosotros, pero definido en un sí mismo en formación.

\subsection{Formación y/o Educación}

Toda acción surge de una intención. La educación tiene su génesis específica en la historia del hombre, con el objetivo de preservar la cultura y el saber hacer. La educación tiene una tradición, un presente y un porvenir. En el análisis de estos conceptos, se reconoce la historia, la actualidad y la educación hacia el futuro. El hombre debe transformarse en sujeto para acceder a la verdad, utilizando los medios y acciones a su alcance para trascender, lo que constituye su formación. El sujeto accede a saberes en la búsqueda de significados, es partícipe en procesos de interacción y trabajo sobre sí mismo, está en proceso de formación.

Entre educación y formación se encuentran construcciones de diferentes sentidos e intenciones. La educación vista como la formación, deviene del sujeto en un trabajo sobre sí mismo, en una transformación basada en el saber, en un trascender, más allá de la educación, pero con ella. La educación desde el punto de vista escolar merece ser vista como un aparato o sistema donde los sujetos son cosificados, se constituyen en un número, en un resultado, donde todos reciben lo mismo y todos deben tener res- puestas similares. Allí la formación se abre paso en la construcción de un sujeto en un trabajo sobre sí mismo, pero con los otros, dando sentido y significado a su actuar.

2. Educación o formación en la escuela normal

La referencia hacia la Escuela Normal, se constituye en una apreciación sobre un proceso de formación docente, la institución tiene ese papel ante la sociedad. Así la institución educativa, porque así se constituye e instituye, tiene "la misión" de formar docentes y este sentido da la dirección adecuada en el camino de la formación. Así la Escuela Normal se constituye en una "ocasión para formarse", sin duda en un espacio donde confluyen la interacción, el lenguaje y el trabajo, el lugar donde se posibilitan una serie de mediaciones que conllevan un proceso; donde el sujeto tiene la "tarea de formarse" en un "trabajo sobre sí mismo, libremente imaginado, pensado, perseguido, realizado a través de medios que se ofrecen o que uno mismo se procura" (Ferry, 1990: 42).

En la Escuela se gestan procesos educativos, donde el sujeto está inmerso, experimenta situaciones, confluyen saberes, representaciones, sentidos, en un habi$t u s^{2}$ que legitima su proceso. Lhotellier, enuncia: "la formación es la capacidad de transformar en experiencia significativa los acontecimientos cotidianos, en el horizonte de un proyecto personal y colectivo" (Honore, 1980: 20). Así entonces, la Institución educativa formadora de docentes debiera participar de ello, hacer del mundo de la vida al interior del aula algo significa- 
tivo en todo momento. La Escuela Normal constituye un espacio de formación de docentes para la sociedad, incluso como un dispositivo.

El plantear educación o formación no significa que exista una relación asimétrica entre los conceptos. Se generan, como categorías que surgen incluso desde una subjetivación, como aquello donde se plasma la subjetividad formada a partir de una episteme, que aflora con diferentes dispositivos, que van desde una arqueología donde lo que configura es el análisis epistemológico del saber con su objetivo de análisis de formación discursiva trasladándose a tomar como "núcleo de estudio las relaciones de poder que subyacen a los discursos" (Moro, 2003: 2).

\subsection{Dispositivos de formación}

El concepto foucaltiano de dispositivo, introduce la existencia de procesos de subjetivación, incorpora líneas de subjetivación a través de las cuales el individuo se convierte en sujeto/objeto de conocimiento y define procesos. El dispositivo automatiza y desindividualiza el poder, son "mecanismos menudos, cotidianos y físicos, todos esos sistemas de micropoder esencialmente inigualitarios y disimétricos que constituyen las disciplinas" (Foucault, 1975: 207). En la escuela se tejen una trama de relaciones de poder y saber, que se construyen y reconstruyen en el tiempo y que por ende atraviesan el proceso de formación.

Un dispositivo es un instrumento de coerción, de imposición, no siempre visible como en el examen. Es una herramienta que regula, que vigila, con un funcionamiento punitivo que normaliza, coacciona acciones y relaciones. La subjetividad en la escuela la producen los dispositivos, subjetivándose y presentándose al mundo. Comprender el rol que emerge de conceptos o nociones como episteme, paradigma, dispositivo, obstáculo, abre sentidos para avanzar e ir encontrando sentido, para rescatar de allí una forma de ver, hacer y ser en el campo de la formación, para tomar distancia y ordenar un espacio discursivo. La objetivación que se produce es una forma de racionalidad, donde aparecen diferentes dispositivos que articulan saber y poder en relación con la subjetivación.

Las formas de conducir los procesos áulicos, la hora de entrada y salida, el uniforme escolar, los procesos de evaluación de una manera y no de otra, son dispositivos que incluso constituyen a otros como vigilar y ordenar. Las prácticas sociales producen discursos que se constituyen incluso en dispositivos que configuran prácticas específicas. Si bien es cierto el individuo no puede formarse por la simple existencia de un dispositivo. Sí, la Escuela Normal se constituye en el espacio por excelencia, donde se liga la formación en una institución de orden educativo y se sintetizan las relaciones o procesos, donde se integran diferentes dispositivos, que el sujeto sin duda "integra" y "transforma". El dispositivo conforma una subjetividad que se produce objetivándose en el actuar.

\subsection{El formador de formadores en la construcción del sujeto}

Ante la cuestión ¿¿cuál es el papel del formador de formadores en la construcción 
del sujeto? se entra en un ámbito de sentido respecto a la noción de sujeto que se puede construir. Como la de un ser en potencia, con necesidades y posibilidades en una sociedad que le facilita para la acción, pero a la vez que ejerce control. Un ser que se transforma para acceder a la verdad, se escapa y al mismo tiempo trasciende, posee voluntad para, además, al mismo tiempo configurar su historia. Al sobrepasar al ello y poseer libertad, se traspasa su posición en un espacio y tiempo; posee conciencia de sí y para sí, en acceso a la espiritualidad.

El papel del formador de docentes en la construcción del sujeto consiste en "irrumpir en su quietud, en su serenidad" conflictuarle, provocar que surja un sujeto de aprendizaje con sentido hacia la libertad en función de sus necesidades, sin dejar de lado las ilusiones, las esperanzas, reconociéndolas en su justa dimensión. El sujeto está determinado por el acceso a la verdad que le ilumina, además en su paso a la espiritualidad. A la creación de la conciencia en sí y para sí. Aprender implica transformarse, se tienen necesidades de aprendizaje precisadas desde el sujeto, que posibilitan la potenciación de un accionar en torno a re-significar un mundo de vida.

El docente de educación normal posee un compromiso que replantea y viabiliza la resignificación de su práctica como sujeto, haciendo conciencia del papel que ello representa para la sociedad de la que forma parte. Para los formadores buscar perspectivas de aprendizaje desde las necesidades reales de formación, debiera ser una estrategia educativa, como sujetos que potencien y transformen las concepciones de realidad sustentada, no solo en resultados escolares, sino en un análisis de accionar cotidiano, de resignificar la práctica a la luz de posturas epistemológicas y pedagógicas, entendiendo que permean la escuela y permiten leer la realidad para proyectarla hacia un mundo de vida diferente.

En la formación de docentes, el formador es un sujeto pedagógico en dos sentidos, de potenciación para aprender, con interés en sí mismo y en los otros; no solo con atención al cultivo del saber y conocer, también de la espiritualidad (Foucault, 2002). Los docentes en formación han de ser sujetos que reconviertan la mirada, que trasciendan, aprendan para transformar una práctica sin quesea parte de un discurso, resignificar y traspasar fronteras, el análisis del quehacer educativo, del actuar propio y de los otros, en relación dinámica de trabajo, de y con los otros, compartir saberes, significados y accionar, aprender de y con los otros.

Es importante pensar en constituir y constituirse en un sujeto epistémico -en tanto habilitado para determinados modos de conocer- a partir de procesos de formación y apropiación que posibilita el hecho educativo. El pensamiento crítico se debe orientar hacia la reflexión epistemológica de un discurso educativo identificado con el mundo de vida de los sujetos sociales, de lo contrario, los saberes se producen, distribuyen, circulan y consumen como mero protocolo para la acreditación administrativa que otorga la Escuela. Interrogar a su vez la validez y pertinencia de los procesos psicológicos, pedagógicos y sociológicos que toda Institución educativa intenta pro- 
mover, reclaman lo epistemológico.

Por un lado, es importante encontrar el fundamento racional de la vida cotidiana, del sentido común con toda su complejidad, en un tiempo, espacio y discurso político; pero también en la experiencia y en los procesos de interacción al interior de las aulas escolares de Educación Normal. Éstas no sólo emergen de la inmediatez apropiada y aprendida, sino de una predeterminación condicionada, pensada o no, que requiere un explicitación como parte de un fenómeno con su propio significado en el mundo de la vida con los otros, los involucrados en ella.

\section{Conclusiones}

En las Escuelas aparecen discursos políticos que tutelan un actuar y direccionan dispositivos. El formador debe buscar el sentido en su actuación, en un proceso circular y complejo donde se genere conocimiento a partir de la experiencia. Implicarse en procesos para partir de la teoría a la práctica, de la experiencia a la práctica y a la teoría y de ésta a la reflexión, lo que supone una valoración y toma de conciencia de un actuar cotidiano. La formación se da en una relación "para", en concordancia con objetivos que se pretenden alcanzar, como una acción que emerge proyectada con ese "fiat voluntario" que plantea Schütz (2008: 88) de un modo que el sujeto que vive de su acción en curso, le da sentido y significado.

En una institución educativa el sujeto se forma con los otros, encuentra los motivos "para" en una relación intersubjetiva, no sujeta exclusivamente al aula de clases. La formación es una relación constitutiva del ser humano, no se circunscribe a un tiempo o espacio, pero los requiere como acción social. También "la formación concierne al porvenir del hombre de manera mucho más profunda, más radical, más esencial que cualquier otro campo de acción del que hasta ahora se hace de la experiencia" (Honoré, 1980: 19). La formación se constituye en un proceso dinámico del exterior, como acción social con los otros y en el interior, bajo nuevos significados y relaciones.

El proceso de formación también se constituye por diferentes prácticas discursivas que le configuran, le constituye en formal y fundamenta al sistema y a la escuela; allí se conforman aún más las relaciones de saber y poder, de allí el sujeto aprende y reproduce. La escuela normal está instituida en algún sentido como las de educación básica, con sus mismos discursos, "reclutamientos", ejercicios de poder y de saber, solo irrumpe allí la intención, la experiencia y el sentido que le da quien desea ser formado y no solo educado.

La formación no es solo posesión de algunos, o algo que se consigue con un título profesional, es una característica propia de la persona que además le constituye como sujeto que se cultiva y se puede desplegar, no tiene espacio o tiempo, edad o escuela. Es necesario reconocer que es erróneo querer ver en lo real la razón determinante de la objetividad, cuando solo se aporta la prueba de una objetivación correcta, que es lo que buscamos aquí, el sentido de lo real en tanto dos conceptos que se subjetivan en una práctica conjunta. Bachelard (1986) plantea una ruptura epistemológi- 
ca, el yuxtaponer teorías opuestas buscando comprender la realidad, acercándose a la razón en un hecho problemático que se busca complejizar.

\section{Notas}

1 Foucault señala al Dispositivo como "conjunto heterogéneo de elementos que incluye discursos, instituciones, reglamentos, leyes, medidas administrativas, enunciados científicos, proposiciones filosóficas y morales. filantrópicas; en resumen: los elementos del dispositivo pertenecen tanto a lo dicho como a lo no dicho. El dispositivo es la red que puede establecerse entre estos elementos" (Foucault, 1991: 128).

2 Se rescata el término habitus como principio generador de prácticas distintas y distintivas... pero también son esquemas clasificatorios, principios de clasificación, principios de visión y de división, aficiones diferentes. "Establecen diferencia entre lo que es bueno y lo que es malo, entre lo que está bien y está mal, entre lo que es distinguido y lo que es vulgar... pero no son las mismas diferencias para unos y otros..." (Bourdieu, 2003: 183).

\section{Bibliografía}

Bachelard, G. (1986) La formación del espíritu científico. Siglo XXI: Buenos Aires.

Benner, D. (1998) La Pedagogía como ciencia. Pomares Corredor: Barcelona.
Cabedo, M.A.y Gil, J. (2013) Cultura para la convivencia. Nau Libres: Valencia.

Delors, J. (1994) La educación encierra un tesoro. Santillana, UNESCO: Madrid.

Elliot, A. (1995) Teoría social y psicoanálisis en transición. Sujeto y sociedad de Freud a Kristeva. Amorrortu editores: Buenos Aires.

Ferry, G. (1990) El trayecto de la formación. Los enseñantes entre la teoría y la práctica. Paidós: México.

Foucault, M. (1975) Vigilar y castigar. Siglo XXI: Argentina.

Foucault, M. (2002) La hermenéutica del Sujeto. Fondo de Cultura Económica: México.

Gadamer, Hans-Georg (1988) Verdad y método I. Sígueme: Salamanca.

Honore, B. (1980) Para una teoría de la formación. Dinámica de la normatividad. Narcea, S. A. ediciones: Madrid.

Moro, Ó. (2003) Michel Foucault: de la episteme al dispositif, en Filosofía Univ. Revista XLI (104). JulioDiciembre 2006: Costa Rica.

Schütz, A. (2008) El problema de la realidad social. Escritos I. Amorrortu: Buenos Aires.

Sobrino, M. Á. (2011) En torno a la Paideia. Isocrática, Platónica y Aristotélica. Instituto Superior de Ciencias de la Educación: México.

Zambrano, A. (2007) Formación, experiencia, saber. Magisterio. Colección Seminarium: Colombia. 